\title{
Coupled fixed point theorems for single-valued operators in $b$-metric spaces
}

\author{
Monica-Felicia Bota ${ }^{1}$, Adrian Petruşel ${ }^{1 *}$, Gabriela Petruşel ${ }^{2}$ and Bessem Samet ${ }^{3}$
}

"Correspondence:

petrusel@math.ubbcluj.ro

${ }^{1}$ Faculty of Mathematics and

Computer Science, Babeş-Bolyai

University Cluj-Napoca,

Kogălniceanu Street, No. 1,

Cluj-Napoca, Romania

Full list of author information is

available at the end of the article

\begin{abstract}
The aim of this paper to present fixed point results for single-valued operators in $b$-metric spaces. The case of scalar metric and the case of vector-valued metric approaches are considered. As an application, a system of integral equations is studied.
\end{abstract}

MSC: $47 \mathrm{H} 10 ; 54 \mathrm{H} 25$

Keywords: single-valued operator; vector-valued metric; fixed point; ordered metric space; coupled fixed point; integral equation; Ulam-Hyers stability

\section{Introduction and preliminaries}

It is well known that Banach's contraction principle for single-valued contractions was extended to several types of generalized metric spaces.

An interesting extension to the case of spaces endowed with vector-valued metrics was done by Perov [1]. Many other contributions on this topic are known now; see, for example, [2-7].

Another extension of the Banach contraction principle was given for the case of socalled $b$-metric spaces (also called quasimetric spaces), starting with some results given by Czerwik; see [8]. For previous results on $b$-metric spaces or extensions of this concept see also Bourbaki [9], Bakhtin [10], Blumenthal [11], among others.

The concept of coupled fixed point and the study of coupled fixed point problems appeared for the first time in some papers of Opoitsev (see [12-14]), while the topic expanded with the work of Guo and Lakshmikantham (see [15]), where the monotone iterations technique is exploited.

If $(X, d)$ is a metric space and $T: X \times X \rightarrow X$ is an operator, then, by definition, a coupled fixed point for $T$ is a pair $\left(x^{*}, y^{*}\right) \in X \times X$ satisfying

$$
\left\{\begin{array}{l}
x^{*}=T\left(x^{*}, y^{*}\right), \\
y^{*}=T\left(y^{*}, x^{*}\right) .
\end{array}\right.
$$

Several years later, the theory of coupled fixed points in the setting of an ordered metric space and under some contractive type conditions on the operator $T$ was re-considered by Gnana Bhaskar and Lakshmikantham in [16] (see also Lakshmikantham and Ćirić in [17]). For other results on coupled fixed point theory see [4, 16-21], among others.

(c) 2015 Bota et al. This article is distributed under the terms of the Creative Commons Attribution 4.0 International License (http://creativecommons.org/licenses/by/4.0/), which permits unrestricted use, distribution, and reproduction in any medium, provided you give appropriate credit to the original author(s) and the source, provide a link to the Creative Commons license, and indicate if changes were made. 
The aim of this paper is to present some fixed point theorems for single-valued operators in $b$-metric spaces with applications to a system of integral equations.

We denote by $M_{m m}\left(\mathbb{R}_{+}\right)$the set of all $m \times m$ matrices with positive elements, by $I$ the identity $m \times m$ matrix and by $O_{m}$ the null $m \times m$ matrix. If $x, y \in \mathbb{R}^{m}, x=\left(x_{1}, \ldots, x_{m}\right)$ and $y=\left(y_{1}, \ldots, y_{m}\right)$, then, by definition,

$$
x \leq y \quad \text { if and only if } \quad x_{i} \leq y_{i} \quad \text { for } i \in\{1,2, \ldots, m\} .
$$

Throughout this paper we will make an identification between row and column vectors in $\mathbb{R}^{m}$.

Let us recall first some important preliminary concepts and results. Let $X$ be a nonempty set. A mapping $d: X \times X \rightarrow \mathbb{R}^{m}$ is called a vector-valued metric on $X$ if the following properties are satisfied: (a) $d(x, y) \geq O$ for all $x, y \in X$; if $d(x, y)=O$, then $x=y$ (where $O:=\underbrace{(0,0, \ldots, 0)}_{m \text {-times }})$;

(b) $d(x, y)=d(y, x)$ for all $x, y \in X$;

(c) $d(x, y) \leq d(x, z)+d(z, y)$ for all $x, y, z \in X$.

A nonempty set $X$ endowed with a vector-valued metric $d$ is called a generalized metric space in the sense of Perov (in short, a generalized metric space) and it will be denoted by $(X, d)$. The usual notions of analysis (such as convergent sequence, Cauchy sequence, completeness, open subset, closed set, open and closed ball, etc.) are defined similarly to the case of metric spaces.

Notice that the generalized metric space in the sense of Perov is a particular case of the so-called cone metric spaces (or $K$-metric space); see [22].

Definition 1.1 A square matrix of real numbers is said to be convergent to zero if and only if all the eigenvalues of $A$ are in the open unit disc (see, for example, [23]).

A classical result in matrix analysis is the following theorem (see, for example, [23, 24]).

Theorem 1.2 Let $A \in M_{m m}\left(\mathbb{R}_{+}\right)$. The following assertions are equivalent:

(i) $A$ is convergent toward zero;

(ii) the spectral radius $\rho(A)$ is strictly less than 1 ;

(iii) $A^{n} \rightarrow O_{m}$ as $n \rightarrow \infty$;

(iv) the matrix $(I-A)$ is nonsingular and

$$
(I-A)^{-1}=I+A+\cdots+A^{n}+\cdots ;
$$

(v) the matrix $(I-A)$ is nonsingular and $(I-A)^{-1}$ has nonnegative elements;

(vi) $A^{n} q$ and $q A^{n}$ are convergent toward zero as $n \rightarrow \infty$, for each $q \in \mathbb{R}^{m}$.

Remark 1.3 Notice also that if $A, B \in M_{m m}\left(\mathbb{R}_{+}\right)$with $A \leq B$ (in the component-wise meaning), then $\rho(B)<1$ implies $\rho(A)<1$.

We will recall now the definition of a $b$-metric space. 
Definition 1.4 (Bakhtin [10], Czerwik [8]) Let $X$ be a set and let $s \geq 1$ be a given real number. A functional $d: X \times X \rightarrow \mathbb{R}_{+}$is said to be a $b$-metric if the following conditions are satisfied:

1. if $x, y \in X$, then $d(x, y)=0$ if and only if $x=y$;

2. $d(x, y)=d(y, x)$, for all $x, y \in X$;

3. $d(x, z) \leq s[d(x, y)+d(y, z)]$, for all $x, y, z \in X$.

A pair $(X, d)$ is called a $b$-metric space.

Some examples of $b$-metric spaces are given in $[8,20,25]$, among others.

If $X$ is a nonempty set and $f: X \rightarrow X$ is a single-valued operator, then we denote by

$$
\operatorname{Fix}(f):=\{x \in X: x=f(x)\},
$$

the fixed point set for $f$ and by

$$
I(f):=\{Y \subset X: f(Y) \subset Y\}
$$

the set of all invariant subsets of $X$ with respect to $f$.

\section{Coupled fixed points for mixed monotone single-valued operators}

In this section, we will prove some coupled fixed point theorem for mixed monotone operators in complete $b$-metric spaces. The approach is based on the iterative construction of a Cauchy successive approximations sequence.

Definition 2.1 Let $(X, \leq)$ a partially ordered set and $T: X \times X \rightarrow X$. We say that $T$ has the mixed monotone property if $T(\cdot, y)$ is monotone increasing for any $y \in X$ and $T(x, \cdot)$ is monotone decreasing for any $y \in X$.

Let $(X, \leq)$ be a partially ordered set. Even though the notation is the same, we make distinction between the partial order on $X$ and the partial order relation on $\mathbb{R}$. Notice also that we can endow the product space $X \times X$ with the following partial order:

$$
\text { for }(x, y),(u, v) \in X \times X, \quad(x, y) \leq_{P}(u, v) \quad \Leftrightarrow \quad x \leq u, y \geq v .
$$

Our first main result is the following.

Theorem 2.2 Let $(X, d)$ be a complete b-metric space with $s \geq 1$ and $T: X \times X \rightarrow X$ a continuous mapping with the mixed monotone property on $X \times X$. Assume that the following conditions are satisfied:

(i) there exists $k \in\left[0, \frac{1}{s}\right)$ such that

$$
d(T(x, y), T(u, v)) \leq \frac{k}{2}[d(x, u)+d(y, v)], \quad \forall x \geq u, y \leq v ;
$$

(ii) there exists $x_{0}, y_{0} \in X$ such that $x_{0} \leq T\left(x_{0}, y_{0}\right)$ and $y_{0} \geq T\left(y_{0}, x_{0}\right)$.

Then there exist $x, y \in X$ such that $x=T(x, y)$ and $y=T(y, x)$. 
If, in addition, the b-metric $d$ is continuous, then we have

$$
\begin{aligned}
& d\left(T^{n}\left(x_{0}, y_{0}\right), x\right) \leq \frac{s k^{n}}{2(1-s k)}\left[d\left(T\left(x_{0}, y_{0}\right), x_{0}\right)+d\left(T\left(y_{0}, x_{0}\right), y_{0}\right)\right], \\
& d\left(T^{n}\left(y_{0}, x_{0}\right), y\right) \leq \frac{s k^{n}}{2(1-s k)}\left[d\left(T\left(x_{0}, y_{0}\right), x_{0}\right)+d\left(T\left(y_{0}, x_{0}\right), y_{0}\right)\right],
\end{aligned}
$$

where $T^{n+1}(x, y):=T\left(T^{n}(x, y), T^{n}(y, x)\right)$, for $(x, y) \in X \times X$ and $n \in \mathbb{N}^{*}$.

Proof Since $x_{0} \leq T\left(x_{0}, y_{0}\right):=x_{1}$ and $y_{0} \geq T\left(y_{0}, x_{0}\right):=y_{1}$ we have $\left(x_{0}, y_{0}\right) \leq_{P}\left(x_{1}, y_{1}\right)$.

If we define $x_{2}:=T\left(x_{1}, y_{1}\right)$ and $y_{2}:=T\left(y_{1}, x_{1}\right)$, then we get

$$
x_{2}=T\left(x_{1}, y_{1}\right)=T\left(T\left(x_{0}, y_{0}\right), T\left(y_{0}, x_{0}\right)\right):=T^{2}\left(x_{0}, y_{0}\right)
$$

and

$$
y_{2}=T\left(y_{1}, x_{1}\right)=T\left(T\left(y_{0}, x_{0}\right), T\left(x_{0}, y_{0}\right)\right):=T^{2}\left(y_{0}, x_{0}\right) .
$$

With these notations, due to the mixed monotone property of $T$, we can prove that

$$
x_{2}=T\left(x_{1}, y_{1}\right) \geq T\left(x_{0}, y_{0}\right)=x_{1}
$$

and

$$
y_{2}=T\left(y_{1}, x_{1}\right) \leq T\left(y_{0}, x_{0}\right)=y_{1} .
$$

Indeed, for $T\left(x_{1}, y_{1}\right) \geq T\left(x_{0}, y_{0}\right)$, let us notice that, from $\left(x_{0}, y_{0}\right) \leq_{P}\left(x_{1}, y_{1}\right)$, using the mixed monotone property, we have $T\left(x_{0}, y\right) \leq T\left(x_{1}, y\right)$, for any $y \in X$ and $T\left(x, y_{0}\right) \leq T\left(x, y_{1}\right)$, for any $x \in X$. Thus, for $y:=y_{0}$ and $x:=x_{1}$ and using the transitivity we obtain $T\left(x_{0}, y_{0}\right) \leq$ $T\left(x_{1}, y_{1}\right)$.

In a similar way one can prove the inequality $T\left(y_{1}, x_{1}\right) \leq T\left(y_{0}, x_{0}\right)$. Indeed, from $\left(x_{0}, y_{0}\right) \leq_{P}\left(x_{1}, y_{1}\right)$, using the mixed monotone property for $T$, we have $T\left(y_{1}, x\right) \leq T\left(y_{0}, x\right)$, for any $x \in X$ and $T\left(y, x_{1}\right) \leq T\left(y, x_{0}\right)$, for any $y \in X$. Choosing $y:=y_{0}$ and $x:=x_{1}$ and using the transitivity, we obtain $T\left(y_{1}, x_{1}\right) \leq T\left(y_{0}, x_{0}\right)$.

We can easily verify that

$$
x_{0} \leq T\left(x_{0}, y_{0}\right)=x_{1} \leq T^{2}\left(x_{0}, y_{0}\right)=x_{2} \leq \cdots \leq T^{n+1}\left(x_{0}, y_{0}\right)=x_{n+1} \leq \cdots
$$

and

$$
y_{0} \geq T\left(y_{0}, x_{0}\right)=y_{1} \geq T^{2}\left(y_{0}, x_{0}\right)=y_{2} \geq \cdots \geq T^{n+1}\left(y_{0}, x_{0}\right)=y_{n+1} \geq \cdots,
$$

where $T^{n+1}(x, y):=T\left(T^{n}(x, y), T^{n}(y, x)\right)$.

Now we claim that, for $n \in \mathbb{N}$, one has the relations

$$
\begin{aligned}
& d\left(T^{n+1}\left(x_{0}, y_{0}\right), T^{n}\left(x_{0}, y_{0}\right)\right) \\
& \quad=d\left(T\left(T^{n}\left(x_{0}, y_{0}\right), T^{n}\left(y_{0}, x_{0}\right)\right), T\left(T^{n-1}\left(x_{0}, y_{0}\right), T^{n-1}\left(y_{0}, x_{0}\right)\right)\right)
\end{aligned}
$$




$$
\begin{aligned}
\leq & \frac{k}{2}\left[d\left(T^{n}\left(x_{0}, y_{0}\right)\right), T^{n-1}\left(x_{0}, y_{0}\right)+d\left(T^{n}\left(y_{0}, x_{0}\right), T^{n-1}\left(y_{0}, x_{0}\right)\right)\right] \\
= & \frac{k}{2}\left[d\left(T\left(T^{n-1}\left(x_{0}, y_{0}\right), T^{n-1}\left(y_{0}, x_{0}\right)\right), T\left(T^{n-2}\left(x_{0}, y_{0}\right), T^{n-2}\left(y_{0}, x_{0}\right)\right)\right)\right. \\
& \left.+d\left(T\left(T^{n-1}\left(y_{0}, x_{0}\right), T^{n-1}\left(x_{0}, y_{0}\right)\right), T\left(T^{n-2}\left(y_{0}, x_{0}\right), T^{n-2}\left(x_{0}, y_{0}\right)\right)\right)\right] \\
\leq & \frac{k}{2}\left[\frac{k}{2}\left(d\left(T^{n-1}\left(x_{0}, y_{0}\right), T^{n-2}\left(x_{0}, y_{0}\right)\right)+d\left(T^{n-1}\left(y_{0}, x_{0}\right), T^{n-2}\left(y_{0}, x_{0}\right)\right)\right)\right. \\
& \left.+\frac{k}{2}\left(d\left(T^{n-1}\left(y_{0}, x_{0}\right), T^{n-2}\left(y_{0}, x_{0}\right)\right)+d\left(T^{n-1}\left(x_{0}, y_{0}\right), T^{n-2}\left(x_{0}, y_{0}\right)\right)\right)\right]
\end{aligned}
$$

We obtain the following inequalities:

$$
d\left(T^{n+1}\left(x_{0}, y_{0}\right), T^{n}\left(x_{0}, y_{0}\right)\right) \leq \frac{k^{n}}{2}\left[d\left(T\left(x_{0}, y_{0}\right), x_{0}\right)+d\left(T\left(y_{0}, x_{0}\right), y_{0}\right)\right]
$$

and

$$
d\left(T^{n+1}\left(y_{0}, x_{0}\right), T^{n}\left(y_{0}, x_{0}\right)\right) \leq \frac{k^{n}}{2}\left[d\left(T\left(y_{0}, x_{0}\right), y_{0}\right)+d\left(T\left(x_{0}, y_{0}\right), x_{0}\right)\right]
$$

Indeed, for $n=1$, since $T\left(x_{0}, y_{0}\right) \geq x_{0}$ and $T\left(y_{0}, x_{0}\right) \leq y_{0}$ we get

$$
d\left(T^{2}\left(x_{0}, y_{0}\right), T\left(x_{0}, y_{0}\right)\right) \leq \frac{k}{2}\left[d\left(T\left(x_{0}, y_{0}\right), x_{0}\right)+d\left(T\left(y_{0}, x_{0}\right), y_{0}\right)\right]
$$

In a similar way, we have

$$
d\left(T^{2}\left(y_{0}, x_{0}\right), T\left(y_{0}, x_{0}\right)\right) \leq \frac{k}{2}\left[d\left(T\left(y_{0}, x_{0}\right), y_{0}\right)+d\left(T\left(x_{0}, y_{0}\right), x_{0}\right)\right]
$$

Now we assume that (3) and (4) hold. Using the inequalities

$$
T^{n+1}\left(x_{0}, y_{0}\right) \geq T^{n}\left(x_{0}, y_{0}\right)
$$

and

$$
T^{n+1}\left(y_{0}, x_{0}\right) \leq T^{n}\left(y_{0}, x_{0}\right)
$$

we get the induction step $P(n+1)$. Indeed, we have

$$
\begin{aligned}
d( & \left.T^{n+2}\left(x_{0}, y_{0}\right), T^{n+1}\left(x_{0}, y_{0}\right)\right) \\
= & d\left(T\left(T^{n+1}\left(x_{0}, y_{0}\right), T^{n+1}\left(y_{0}, x_{0}\right)\right), T\left(T^{n}\left(x_{0}, y_{0}\right), T^{n}\left(y_{0}, x_{0}\right)\right)\right) \\
\leq & \frac{k}{2}\left[d\left(T^{n+1}\left(x_{0}, y_{0}\right), T^{n}\left(x_{0}, y_{0}\right)\right)+d\left(T^{n+1}\left(y_{0}, x_{0}\right), T^{n}\left(y_{0}, x_{0}\right)\right)\right] \\
\leq & \frac{k}{2}\left\{\frac{k^{n}}{2}\left[d\left(T\left(x_{0}, y_{0}\right), x_{0}\right)+d\left(T\left(y_{0}, x_{0}\right), y_{0}\right)\right]\right. \\
& \left.+\frac{k^{n}}{2}\left[d\left(T\left(y_{0}, x_{0}\right), y_{0}\right)+d\left(T\left(x_{0}, y_{0}\right), x_{0}\right)\right]\right\} \\
= & \frac{k^{n+1}}{2}\left[d\left(T\left(x_{0}, y_{0}\right), x_{0}\right)+d\left(T\left(y_{0}, x_{0}\right), y_{0}\right)\right] .
\end{aligned}
$$


Similarly, we have

$$
\begin{aligned}
d( & \left.T^{n+2}\left(y_{0}, x_{0}\right), T^{n+1}\left(y_{0}, x_{0}\right)\right) \\
= & d\left(T\left(T^{n+1}\left(y_{0}, x_{0}\right), T^{n+1}\left(x_{0}, y_{0}\right)\right), T\left(T^{n}\left(y_{0}, x_{0}\right), T^{n}\left(x_{0}, y_{0}\right)\right)\right) \\
\leq & \frac{k}{2}\left[d\left(T^{n+1}\left(y_{0}, x_{0}\right), T^{n}\left(y_{0}, x_{0}\right)\right)+d\left(T^{n+1}\left(x_{0}, y_{0}\right), T^{n}\left(x_{0}, y_{0}\right)\right)\right] \\
\leq & \frac{k}{2}\left\{\frac{k^{n}}{2}\left[d\left(T\left(y_{0}, x_{0}\right), y_{0}\right)+d\left(T\left(x_{0}, y_{0}\right), x_{0}\right)\right]\right. \\
& \left.+\frac{k^{n}}{2}\left[d\left(T\left(x_{0}, y_{0}\right), x_{0}\right)+d\left(T\left(y_{0}, x_{0}\right), y_{0}\right)\right]\right\} \\
= & \frac{k^{n+1}}{2}\left[d\left(T\left(y_{0}, x_{0}\right), y_{0}\right)+d\left(T\left(x_{0}, y_{0}\right), x_{0}\right)\right] .
\end{aligned}
$$

This implies that $\left(T^{n}\left(x_{0}, y_{0}\right)\right)$ and $\left(T^{n}\left(y_{0}, x_{0}\right)\right)$ are Cauchy sequences in $X$. Indeed, we have

$$
\begin{aligned}
d( & \left.T^{n}\left(x_{0}, y_{0}\right), T^{n+p}\left(x_{0}, y_{0}\right)\right) \\
\leq & s\left[d\left(T^{n}\left(x_{0}, y_{0}\right), T^{n+1}\left(x_{0}, y_{0}\right)\right)+d\left(T^{n+1}\left(x_{0}, y_{0}\right), T^{n+p}\left(x_{0}, y_{0}\right)\right)\right] \\
\leq & s d\left(T^{n}\left(x_{0}, y_{0}\right), T^{n+1}\left(x_{0}, y_{0}\right)\right)+s^{2} d\left(T^{n+1}\left(x_{0}, y_{0}\right), T^{n+2}\left(x_{0}, y_{0}\right)\right)+\cdots \\
& +s^{p-1} d\left(T^{n+p-2}\left(x_{0}, y_{0}\right), T^{n+p-1}\left(x_{0}, y_{0}\right)\right)+s^{p-1} d\left(T^{n+p-1}\left(x_{0}, y_{0}\right), T^{n+p}\left(x_{0}, y_{0}\right)\right) \\
\leq & {\left[s \frac{k^{n}}{2}+s^{2} \frac{k^{n+1}}{2}+\cdots+s^{p-1} \frac{k^{n+p-2}}{2}+s^{p} \frac{k^{n+p-1}}{2}\right] } \\
= & \left.\quad \cdot \frac{k^{n}}{2}\left[1+s k+\cdots+(s k)^{p-2}+(s k)^{p-1}\right] \cdot\left[d\left(T\left(x_{0}, y_{0}\right), x_{0}\right), x_{0}\right)+d\left(T\left(y_{0}, x_{0}\right), y_{0}\right)\right] \\
= & \frac{s k^{n}}{2} \cdot \frac{1-(s k)^{p}}{1-s k} \cdot\left[d\left(T\left(x_{0}, y_{0}\right), x_{0}\right)+d\left(T\left(y_{0}, x_{0}\right), y_{0}\right)\right] \rightarrow 0, \quad \text { as } n \rightarrow+\infty .
\end{aligned}
$$

Similarly we can verify that $\left(T^{n}\left(y_{0}, x_{0}\right)\right)$ is also a Cauchy sequence.

Since $X$ is a complete $b$-metric space and $\left(T^{n}\left(x_{0}, y_{0}\right)\right)$ and $\left(T^{n}\left(y_{0}, x_{0}\right)\right)$ are Cauchy sequences we see that there exist $x^{*}, y^{*} \in X$ such that

$$
\lim _{n \rightarrow \infty} T^{n}\left(x_{0}, y_{0}\right)=x^{*} \text { and } \lim _{n \rightarrow \infty} T^{n}\left(y_{0}, x_{0}\right)=y^{*}
$$

Finally, we claim that $\left(x^{*}, y^{*}\right)$ is a coupled fixed point for $T$.

Since $T$ is continuous at any $(x, y) \in X \times X$, for any $\varepsilon>0$ there exists $\delta>0$ such that, for any $(u, v) \in X \times X$ with

$$
d\left(x^{*}, u\right)+d\left(y^{*}, v\right)<\frac{\delta}{s}, \quad \text { we have } \quad d\left(T\left(x^{*}, y^{*}\right), T(u, v)\right)<\frac{\varepsilon}{2 s} .
$$

Since $T^{n}\left(x_{0}, y_{0}\right) \rightarrow x^{*}$ and $T^{n}\left(y_{0}, x_{0}\right) \rightarrow y^{*}$, for $\eta:=\min \left\{\frac{\varepsilon}{2 s}, \frac{\delta}{2 s}\right\}>0$ there exist $n_{0}, m_{0} \in \mathbb{N}$ such that, for every $n \geq n_{0}, m \geq m_{0}$, we have

$$
d\left(T^{n}\left(x_{0}, y_{0}\right), x^{*}\right)<\eta \quad \text { and } \quad d\left(T^{m}\left(y_{0}, x_{0}\right), y^{*}\right)<\eta
$$


Now, for $n \in \mathbb{N}$ with $n \geq \max \left\{n_{0}, m_{0}\right\}$ we have

$$
\begin{aligned}
d\left(T\left(x^{*}, y^{*}\right), x^{*}\right) & \leq s\left[d\left(T\left(x^{*}, y^{*}\right), T^{n+1}\left(x_{0}, y_{0}\right)\right)+d\left(T^{n+1}\left(x_{0}, y_{0}\right), x^{*}\right)\right] \\
& =s\left[d\left(T\left(x^{*}, y^{*}\right), T\left(T^{n}\left(x_{0}, y_{0}\right), T^{n}\left(y_{0}, x_{0}\right)\right)\right)+d\left(T^{n+1}\left(x_{0}, y_{0}\right), x^{*}\right)\right] \\
& \leq s\left(\frac{\varepsilon}{2 s}+\eta\right) \leq \varepsilon .
\end{aligned}
$$

For the second part of the proof, we will take into account the following inequality:

$$
d\left(T^{n}\left(x_{0}, y_{0}\right), T^{n+p}\left(x_{0}, y_{0}\right)\right) \leq \frac{s k^{n}}{2} \frac{1-(s k)^{p}}{1-s k} \cdot\left[d\left(T\left(x_{0}, y_{0}\right), x_{0}\right)+d\left(T\left(y_{0}, x_{0}\right), y_{0}\right)\right]
$$

Letting $p \rightarrow \infty$ and taking into account that $d$ is continuous, we obtain the conclusion:

$$
d\left(T^{n}\left(x_{0}, y_{0}\right), x^{*}\right) \leq \frac{s k^{n}}{2(1-s k)}\left[d\left(T\left(x_{0}, y_{0}\right), x_{0}\right)+d\left(T\left(y_{0}, x_{0}\right), y_{0}\right)\right]
$$

Similarly, we obtain

$$
d\left(T^{n}\left(y_{0}, x_{0}\right), T^{n+p}\left(y_{0}, x_{0}\right)\right) \leq \frac{s k^{n}}{2} \frac{1-(s k)^{p}}{1-s k} \cdot\left[d\left(T\left(x_{0}, y_{0}\right), x_{0}\right)+d\left(T\left(y_{0}, x_{0}\right), y_{0}\right)\right]
$$

and thus

$$
d\left(T^{n}\left(y_{0}, x_{0}\right), y^{*}\right) \leq \frac{s k^{n}}{2(1-s k)}\left[d\left(T\left(x_{0}, y_{0}\right), x_{0}\right)+d\left(T\left(y_{0}, x_{0}\right), y_{0}\right)\right] .
$$

This completes the proof.

The above results extend some theorems given in [26] for the case of metric spaces. For another contraction type condition and a different approach see [27].

\section{A vector approach in ordered $b$-metric spaces}

Let $X$ be a nonempty set endowed with a partial order relation denoted by $\leq$. We denote

$$
X_{\leq}:=\left\{\left(x_{1}, x_{2}\right) \in X \times X: x_{1} \leq x_{2} \text { or } x_{2} \leq x_{1}\right\}
$$

If $f: X \rightarrow X$ is an operator then we denote the Cartesian product of $f$ with itself as follows:

$$
f \times f: X \times X \rightarrow X \times X, \quad \text { given by }(f \times f)\left(x_{1}, x_{2}\right):=\left(f\left(x_{1}\right), f\left(x_{2}\right)\right) .
$$

Definition 3.1 Let $X$ be a nonempty set. Then $(X, d, \leq)$ is called an ordered generalized $b$-metric space if:

(i) $(X, d)$ is a generalized $b$-metric space in the sense of Perov;

(ii) $(X, \leq)$ is a partially ordered set.

The following result will be an important tool in our approach.

Theorem 3.2 Let $(X, d, \leq)$ be an ordered generalized complete b-metric space with $s \geq 1$ and let $f: X \rightarrow X$ be an operator. We suppose that: 
(1) for each $(x, y) \notin X_{\leq}$there exists $z(x, y):=z \in X$ such that $(x, z),(y, z) \in X_{\leq}$;

(2) $X_{\leq} \in I(f \times f)$;

(3) $f:(X, d) \rightarrow(X, d)$ has closed graph;

(4) there exists $x_{0} \in X$ such that $\left(x_{0}, f\left(x_{0}\right)\right) \in X_{\leq}$;

(5) there exists a matrix $A \in M_{m m}\left(\mathbb{R}_{+}\right)$for which sA converges to zero, such that

$$
d(f(x), f(y)) \leq A d(x, y) \quad \text { for each }(x, y) \in X_{\leq} .
$$

Then $f$ is a Picard operator, i.e., $\operatorname{Fix}(f)=\left\{x^{*}\right\}$ and $f^{n}(x) \rightarrow x^{*}$, as $n \rightarrow \infty$, for every $x \in X$.

Proof Let $x_{0} \in X$ and define $x_{1}:=f\left(x_{0}\right)$. Using the condition (4) from the hypothesis we have $\left(x_{0}, f\left(x_{0}\right)\right) \in X_{\leq}$. Let $x_{n+1}:=f\left(x_{n}\right)$, for $n \in \mathbb{N}^{*}$. We know that $\left(x_{0}, x_{1}\right) \in X_{\leq}$. By (2) we have $\left(f\left(x_{0}\right), f\left(x_{1}\right)\right)=\left(x_{1}, x_{2}\right) \in X_{\leq}$.

We have

$$
d\left(x_{1}, x_{2}\right)=d\left(f\left(x_{0}\right), f\left(x_{1}\right)\right) \leq A d\left(x_{0}, x_{1}\right) .
$$

Let $x_{3}:=f\left(x_{2}\right)$. Since $\left(x_{1}, x_{2}\right) \in X_{\leq}$, we have $\left(f\left(x_{1}\right), f\left(x_{2}\right)\right) \in X_{\leq}$. Thus $\left(x_{2}, x_{3}\right) \in X_{\leq}$and

$$
d\left(x_{2}, x_{3}\right)=d\left(f\left(x_{1}\right), f\left(x_{2}\right)\right) \leq A^{2} d\left(x_{0}, x_{1}\right) .
$$

Thus, for the sequence $x_{n}:=f^{n}\left(x_{0}\right)$ of successive approximations of $f$ starting from $x_{0}$ we have

$$
d\left(x_{n}, x_{n+1}\right) \leq A^{n} d\left(x_{0}, x_{1}\right) \quad \text { for }\left(x_{n}, x_{n+1}\right) \in X_{\leq} .
$$

We prove next that the sequence $\left(x_{n}\right)$ is Cauchy. We have

$$
\begin{aligned}
d\left(x_{n}, x_{n+p}\right) & \leq s d\left(x_{n}, x_{n+1}\right)+s^{2} d\left(x_{n+1}, x_{n+2}\right)+\cdots+s^{p-1} d\left(x_{n+p-1}, x_{n+p}\right) \\
& \leq s A^{n} d\left(x_{0}, x_{1}\right)+s^{2} A^{n+1} d\left(x_{0}, x_{1}\right)+\cdots+s^{p} A^{n+p-1} d\left(x_{0}, x_{1}\right) .
\end{aligned}
$$

Since $s A$ is convergent to zero, by Theorem 1.2, we see that $(I-s A)$ is nonsingular and

$$
(I-s A)^{-1}=I+s A+\cdots+(s A)^{p}+\cdots .
$$

Thus, by the above relation, we get

$$
d\left(x_{n}, x_{n+p}\right) \leq s A^{n}(I-s A)^{-1} d\left(x_{0}, x_{1}\right) .
$$

Notice now that, by Remark 1.3, the matrix $A$ converges to zero too, which implies that $d\left(x_{n}, x_{n+p}\right) \rightarrow 0$ as $n \rightarrow \infty$. Hence the sequence $\left(x_{n}\right)$ is Cauchy. Since the $b$-metric space is complete, there exists $x^{*} \in X$ such that $x_{n} \rightarrow x^{*}$ as $n \rightarrow \infty$.

Using the assumption (3) from the hypothesis we obtain $\operatorname{Fix}(f) \neq \emptyset$.

For the uniqueness of the fixed point, we suppose that there exists $y \in X$ such that $y=f(y)$ and we estimate

$$
d\left(x^{*}, y\right)=d\left(f\left(x^{*}\right), f(y)\right) \leq A d\left(x^{*}, y\right) .
$$

From the fact that $(I-A)$ is nonsingular we have $d\left(x^{*}, y\right)=0$. Hence $x^{*}=y$. 
If $\left(x, x_{0}\right) \in X_{\leq}$then, by (2), we have $\left(f^{n}(x), f^{n}\left(x_{0}\right)\right) \in X_{\leq}, \forall n \in \mathbb{N}$. Thus $f^{n}(x) \rightarrow x^{*}, n \rightarrow \infty$. If $\left(x, x_{0}\right) \notin X_{\leq}$, by (1), there exists $z\left(x, x_{0}\right):=z \in X_{\leq}$such that $(x, z),\left(x_{0}, z\right) \in X_{\leq}$. By the fact that $\left(x_{0}, z\right) \in X_{\leq}$we have $\left(f^{n}\left(x_{0}\right), f^{n}(z)\right) \in X_{\leq}$, which implies that $f^{n}(z) \rightarrow x^{*}, n \rightarrow \infty$. This together with $(x, z) \in X_{\leq}$implies that $f^{n}(x) \rightarrow x^{*}, n \rightarrow \infty$.

Remark 3.3 In particular, if one of the following classical assumptions holds:

$\left(2^{\prime}\right) f:(X, \leq) \rightarrow(X, \leq)$ is monotone increasing

or

$\left(2^{\prime \prime}\right) f:(X, \leq) \rightarrow(X, \leq)$ is monotone decreasing.

Notice that the assertion (2) in Theorem 3.2 is more general.

Remark 3.4 Condition (4) from the above theorem is equivalent with

$\left(4^{\prime}\right) f$ has a lower or an upper fixed point in $X$.

Notice also that the above theorem extends to the case of $b$-metric spaces; a result of this type given in [28].

Definition 3.5 Let $(X, d)$ be a generalized $b$-metric space with constant $s \geq 1$ and $f: X \rightarrow$ $X$ be an operator. The fixed point equation

$$
x=f(x), \quad x \in X,
$$

is called generalized Ulam-Hyers stable if and only if there exists $\psi: \mathbb{R}_{+}^{m} \rightarrow \mathbb{R}_{+}^{m}$ increasing, continuous in 0 and $\psi(0)=0$, such that for each $\varepsilon:=\left(\varepsilon_{1}, \ldots, \varepsilon_{m}\right)$ with $\varepsilon_{i}>0$ for $i \in\{1, \ldots, m\}$ and for each solution $y^{*} \in X$ of the inequality

$$
d(y, f(y)) \leq \varepsilon,
$$

there exists a solution $x^{*}$ of the fixed point equation (5) such that

$$
d\left(y^{*}, x^{*}\right) \leq \psi(\varepsilon)
$$

In particular, if there exists $C \in M_{m, m}\left(\mathbb{R}_{+}\right)$such that $\psi(t):=C \cdot t$, for each $t \in \mathbb{R}_{+}^{m}$, then the fixed point equation (5) is said to be Ulam-Hyers stable.

Theorem 3.6 Let $(X, d)$ be an ordered generalized b-metric space with constant $s \geq 1$ and $f: X \rightarrow X$ be an operator. Suppose that all the hypotheses of Theorem 3.2 hold. Then the fixed point equation (5) is Ulam-Hyers stable.

Proof By Theorem 3.2 we see that $f$ is a Picard operator and hence Fix $(f)=\left\{x^{*}\right\}$. Thus, for any $y^{*} \in X$ with $d\left(y^{*}, f\left(y^{*}\right)\right) \leq \varepsilon$ we have

$$
d\left(y^{*}, x^{*}\right) \leq s\left[d\left(y^{*}, f\left(y^{*}\right)\right)+d\left(f\left(y^{*}\right), f\left(x^{*}\right)\right)\right] \leq s\left[\varepsilon+A d\left(y^{*}, x^{*}\right)\right]
$$


Thus,

$$
d\left(y^{*}, x^{*}\right) \leq(I-s A)^{-1} s \varepsilon .
$$

Let us consider now the case of coupled fixed point problems. Let $(X, d)$ be a $b$-metric space and $T: X \times X \rightarrow X$ be an operator. Then, by definition, a coupled fixed point for $T$ is a pair $\left(x^{*}, y^{*}\right) \in X \times X$ satisfying

$$
\left\{\begin{array}{l}
x^{*}=T\left(x^{*}, y^{*}\right) \\
y^{*}=T\left(y^{*}, x^{*}\right)
\end{array}\right.
$$

We will apply the above results to the above coupled fixed point problem. Our main result concerning the coupled fixed point problem (7) is the following theorem.

Theorem 3.7 Let $(X, d, \leq)$ be an ordered and complete b-metric space with constant $s \geq 1$ and let $T: X \times X \rightarrow X$ be an operator. We suppose:

(i) for each $z, w \in X \times X$ which are not comparable with respect to the partial ordering $\preceq$ on $X \times X$, there exists $t \in X \times X$ (which may depend on $z$ and $w$ ) such that $t$ is comparable (with respect to the partial ordering $\preceq$ ) with both $z$ and $w$;

(ii) $T$ has the generalized mixed monotone property, i.e., for all ( $x \geq u$ and $y \leq v)$ or $(u \geq x$ and $v \leq y)$ we have

$$
\left\{\begin{array} { l } 
{ T ( x , y ) \geq T ( u , v ) , } \\
{ T ( y , x ) \leq T ( v , u ) }
\end{array} \quad \text { or } \quad \left\{\begin{array}{l}
T(u, v) \geq T(x, y), \\
T(v, u) \leq T(y, x)
\end{array}\right.\right.
$$

(iii) $T: X \times X \rightarrow X$ has closed graph;

(iv) there exists $z_{0}:=\left(z_{0}^{1}, z_{0}^{2}\right) \in X \times X$ such that

$$
\left\{\begin{array} { l } 
{ z _ { 0 } ^ { 1 } \geq T ( z _ { 0 } ^ { 1 } , z _ { 0 } ^ { 2 } ) , } \\
{ z _ { 0 } ^ { 2 } \leq T ( z _ { 0 } ^ { 2 } , z _ { 0 } ^ { 1 } ) }
\end{array} \quad \text { or } \quad \left\{\begin{array}{l}
T\left(z_{0}^{1}, z_{0}^{2}\right) \geq z_{0}^{1}, \\
T\left(z_{0}^{2}, z_{0}^{1}\right) \leq z_{0}^{2}
\end{array}\right.\right.
$$

(v) there exist $k_{1}, k_{2} \in \mathbb{R}_{+}$with $k_{1}+k_{2}<\frac{1}{s}$ such that

$$
d(T(x, y), T(u, v)) \leq k_{1} d(x, u)+k_{2} d(y, v)
$$

$$
\text { for all ( } x \geq u \text { and } y \leq v) \text { or }(u \geq x \text { and } v \leq y) \text {. }
$$

Then there exists a unique element $\left(x^{*}, y^{*}\right) \in X \times X$ such that

$$
\left\{\begin{array}{l}
x^{*}=T\left(x^{*}, y^{*}\right) \\
y^{*}=T\left(y^{*}, x^{*}\right)
\end{array}\right.
$$

and the sequence of the successive approximations $\left(T^{n}\left(w_{0}^{1}, w_{0}^{2}\right), T^{n}\left(w_{0}^{2}, w_{0}^{1}\right)\right)$ converges to $\left(x^{*}, y^{*}\right)$ as $n \rightarrow \infty$, for all $\left(w_{0}^{1}, w_{0}^{2}\right) \in X \times X$.

Proof Denote $Z:=X \times X$ and define on $Z$, for $z:=(x, y), w:=(u, v) \in Z$, the partial order relation

$$
z \preceq w \quad \text { if and only if } \quad(x \geq u \text { and } y \leq v) .
$$


We denote

$$
Z_{\preceq}=\{(z, w):=((x, y),(u, v)) \in Z \times Z: z \preceq w \text { or } w \preceq z\} .
$$

Let $F: Z \rightarrow Z$ be an operator defined by

$$
F(x, y):=(T(x, y), T(y, x))
$$

By our assumption (ii), we have $Z_{\leq} \in I(F \times F)$.

Indeed, by our hypotheses, it follows that Theorem 3.2 is applicable for the operator $F$. More precisely, $F$ is a contraction with a matrix

$$
A:=\left(\begin{array}{ll}
k_{1} & k_{2} \\
k_{2} & k_{1}
\end{array}\right),
$$

i.e., we have

$$
\tilde{d}(F(x, y), F(u, v)) \leq A \tilde{d}((x, y),(u, v)) \quad \text { for all }((x, y),(u, v)) \in Z_{\leq}
$$

where the space $Z$ is endowed with the vector-valued $b$-metric $\tilde{d}: Z \times Z \rightarrow \mathbb{R}_{+}^{2}$ by

$$
\tilde{d}((x, y),(u, v)):=\left(\begin{array}{l}
d(x, u) \\
d(y, v)
\end{array}\right) .
$$

Concerning the Ulam-Hyers stability problem for a system of operatorial equations we have the concept.

Definition 3.8 Let $(X, d)$ be a $b$-metric space with constant $s \geq 1$ and let $T_{1}, T_{2}: X \times X \rightarrow$ $X$ be two operators. The operatorial equation system

$$
\left\{\begin{array}{l}
x=T_{1}(x, y), \\
y=T_{2}(x, y),
\end{array}\right.
$$

is called Ulam-Hyers stable if and only if there exist $c_{1}, c_{2}, c_{3}, c_{4}>0$ such that, for each $\varepsilon_{1}, \varepsilon_{2}>0$ and for each solution pair $\left(u^{*}, v^{*}\right) \in X \times X$ of the inequations

$$
\left\{\begin{array}{l}
d\left(u^{*}, T_{1}\left(u^{*}, v^{*}\right)\right) \leq \varepsilon_{1}, \\
d\left(v^{*}, T_{2}\left(u^{*}, v^{*}\right)\right) \leq \varepsilon_{2},
\end{array}\right.
$$

there exists a solution $\left(x^{*}, y^{*}\right) \in X \times X$ of the fixed point system (9) such that

$$
\left\{\begin{array}{l}
d\left(u^{*}, x^{*}\right) \leq c_{1} \varepsilon_{1}+c_{2} \varepsilon_{2}, \\
d\left(v^{*}, y^{*}\right) \leq c_{3} \varepsilon_{1}+c_{4} \varepsilon_{2} .
\end{array}\right.
$$

By Theorem 3.6,we get the following Ulam-Hyers stability result for the coupled fixed point problem. 
Theorem 3.9 Assume that all the assumptions of Theorem 3.7 are satisfied. Then the operatorial equations system

$$
\left\{\begin{array}{l}
x=T(x, y) \\
y=T(y, x)
\end{array}\right.
$$

is Ulam-Hyers stable.

Proof The conclusion follows by Theorem 3.6, applied for the fixed point problem $(x, y)=$ $F(x, y)$, where $F(x, y):=(T(x, y), T(y, x))$.

\section{An application}

We will discuss now an application of the previous result. Let us consider the following system of integral equations:

$$
\left\{\begin{array}{l}
x(t)=g(t)+\int_{0}^{T} G(s, t) f(s, x(s), y(s)) d s \\
y(t)=g(t)+\int_{0}^{T} G(s, t) f(s, y(s), x(s)) d s
\end{array}\right.
$$

where $t \in[0, T]$.

A solution of the above system is a pair $(x, y) \in C[0, T] \times C[0, T]$ satisfying the above relations for all $t \in[0, T]$.

We consider $X:=C[0, T]$ endowed with the partial order relation:

$$
x \leq_{C} y \quad \Leftrightarrow \quad x(t) \leq y(t) \quad \text { for all } t \in[0, T] .
$$

We will also consider the following $b$-metric on $X$ :

$$
d(x, y):=\max _{t \in[0, T]}(x(t)-y(t))^{2} .
$$

Notice that $d$ is a b-metric with constant $s=2$ and $d$ can be represented using the supremum (Cebîşev) type norm by $d(x, y)=\left\|(x-y)^{2}\right\|_{C}$.

Then we have the following existence and uniqueness result.

Theorem 4.1 Consider the integral system (13). We suppose:

(i) $g:[0, T] \rightarrow \mathbb{R}$ and $f:[0, T] \times \mathbb{R}^{2} \rightarrow \mathbb{R}$ are continuous and $G:[0, T] \times[0, T] \rightarrow \mathbb{R}_{+}$ is integrable with respect to the first variable.

(ii) $f(s, \cdot, \cdot)$ has the generalized mixed monotone property with respect to the last two variables for all $s \in[0, T]$.

(iii) There exists $\alpha, \beta:[0, T] \rightarrow \mathbb{R}_{+}$in $L^{1}[0, T]$ such that, for each $u_{1}, u_{2}, v_{1}, v_{2} \in \mathbb{R}$ with $u_{1} \leq v_{1}$ and $u_{2} \geq v_{2}$ (or reversely), we have

$$
\left|f\left(s, u_{1}, u_{2}\right)-f\left(s, v_{1}, v_{2}\right)\right| \leq \alpha(s)\left|u_{1}-v_{1}\right|+\beta(s)\left|u_{2}-v_{2}\right| \quad \text { for each } s \in[0, T] .
$$

(iv) $\max _{t \in[0, T]}\left(\int_{0}^{T} G(s, t) \alpha(s) d s\right)^{2}+\max _{t \in[0, T]}\left(\int_{0}^{T} G(s, t) \beta(s) d s\right)^{2}<\frac{1}{4}$.

(v) There exists $x_{0}, y_{0} \in C[0, T]$ such that

$$
\left\{\begin{array}{l}
x_{0}(t) \leq g(t)+\int_{0}^{T} G(s, t) f\left(s, x_{0}(s), y_{0}(s)\right) d s \\
y_{0}(t) \geq g(t)+\int_{0}^{T} G(s, t) f\left(s, y_{0}(s), x_{0}(s)\right) d s
\end{array}\right.
$$


or

$$
\left\{\begin{array}{l}
x_{0}(t) \geq g(t)+\int_{0}^{T} G(s, t) f\left(s, x_{0}(s), y_{0}(s)\right) d s \\
y_{0}(t) \leq g(t)+\int_{0}^{T} G(s, t) f\left(s, y_{0}(s), x_{0}(s)\right) d s
\end{array}\right.
$$

for all $t \in[0, T]$.

Then there exists a unique solution ( $\left.x^{*}, y^{*}\right)$ of the system (13).

Proof We will work in the space $(X, d)$ with

$$
d(x, y):=\max _{t \in[0, T]}(x(t)-y(t))^{2},
$$

which is a $b$-metric space with $s=2$.

We can prove that all the assumptions of Theorem 3.7 are satisfied. We define $S: X \times$ $X \rightarrow X$ by

$$
S(x, y)(t):=g(t)+\int_{0}^{T} G(s, t) f(s, x(s), y(s)) d s \quad \text { for each } t \in[0, T]
$$

Then system (13) can be written as a coupled fixed point problem for $S$ :

$$
\left\{\begin{array}{l}
x=S(x, y) \\
y=S(y, x)
\end{array}\right.
$$

Then, for all $(x \geq u$ and $y \leq v)$ or $(u \geq x$ and $v \leq y)$, we have

$$
\begin{aligned}
& |S(x, y)(t)-S(u, v)(t)|^{2} \\
& \leq\left[\int_{0}^{T} G(s, t)|f(s, x(s), y(s))-f(s, u(s), v(s))| d s\right]^{2} \\
& \leq\left[\int_{0}^{T} G(s, t)(\alpha(s)|x(s)-u(s)|+\beta(s)|y(s)-v(s)|) d s\right]^{2} \\
& =\left[\int_{0}^{T} G(s, t)\left(\alpha(s) \sqrt{(x(s)-u(s))^{2}}+\beta(s) \sqrt{(y(s)-v(s))^{2}}\right) d s\right]^{2} \\
& =\left[\int_{0}^{T} G(s, t)\left(\alpha(s) \sqrt{|x(s)-u(s)|^{2}}+\beta(s) \sqrt{|y(s)-v(s)|^{2}}\right) d s\right]^{2} \\
& \leq\left[\int_{0}^{T} G(s, t) \alpha(s) \sqrt{\left\|(x-u)^{2}\right\|_{C}} d s+\int_{0}^{T} G(s, t) \beta(s) \sqrt{\left\|(y-v)^{2}\right\|_{C}} d s\right]^{2} \\
& \leq 2\left[\left(\int_{0}^{T} G(s, t) \alpha(s) \sqrt{\left\|(x-u)^{2}\right\|_{C}} d s\right)^{2}+\left(\int_{0}^{T} G(s, t) \beta(s) \sqrt{\left\|(y-v)^{2}\right\|_{C}} d s\right)^{2}\right] \\
& =2\left(\int_{0}^{T} G(s, t) \alpha(s) d s\right)^{2} \cdot\left\|(x-u)^{2}\right\|_{C}+2\left(\int_{0}^{T} G(s, t) \beta(s) d s\right)^{2} \cdot\left\|(y-v)^{2}\right\|_{C} \\
& \leq 2 \max _{t \in[0, T]}\left(\int_{0}^{T} G(s, t) \alpha(s) d s\right)^{2} \cdot\left\|(x-u)^{2}\right\|_{C} \\
& +2 \max _{t \in[0, T]}\left(\int_{0}^{T} G(s, t) \beta(s) d s\right)^{2} \cdot\left\|(y-v)^{2}\right\|_{C} .
\end{aligned}
$$


Thus, taking the maximum over $t \in[0, T]$, we get

$$
\left\|(S(x, y)-S(u, v))^{2}\right\|_{C} \leq k_{1}\left\|(x-u)^{2}\right\|_{C}+k_{2}\left\|(y-v)^{2}\right\|_{C}
$$

where $k_{1}:=2 \max _{t \in[0, T]}\left(\int_{0}^{T} G(s, t) \alpha(s) d s\right)^{2}$ and $k_{2}:=2 \max _{t \in[0, T]}\left(\int_{0}^{T} G(s, t) \beta(s) d s\right)^{2}$.

Hence, for all $(x \geq u$ and $y \leq v)$ or $(u \geq x$ and $v \leq y)$, we get

$$
d(S(x, y), S(u, v)) \leq k_{1} d(x, u)+k_{2} d(y, v) .
$$

Since $k_{1}+k_{2}<\frac{1}{2}$ (by the assumption (iv)), we see that all the assumptions of Theorem 3.7 are satisfied and the conclusion follows.

Remark 4.2 Using Theorem 3.9, the Ulam-Hyers stability of the integral equations system can be established, under similar assumptions. We also mention that the method can be extended to a system of Volterra type integral equations; see for such a result [27].

\section{Competing interests}

The authors declare that they have no competing interests.

\section{Authors' contributions}

M-FB and GP carried out the studies on coupled fixed points for mixed monotone operators and drafted the manuscript. AP and BS carried out the vectorial approach to coupled fixed point theory and the application section. All the authors have equal contributions to this work. All authors read and approved the final manuscript.

\section{Author details}

${ }^{1}$ Faculty of Mathematics and Computer Science, Babeş-Bolyai University Cluj-Napoca, Kogălniceanu Street, No. 1, Cluj-Napoca, Romania. ${ }^{2}$ Faculty of Business, Babeş-Bolyai University Cluj-Napoca, Kogălniceanu Street, No. 1, Cluj-Napoca, Romania. ${ }^{3}$ Department of Mathematics, College of Science, King Saud University, P.O. Box 2455, Riyadh, 11451, Saudi Arabia.

\section{Acknowledgements}

For the first author, this paper was supported by a grant of the Romanian National Authority for Scientific Research, CNCS-UEFISCDI, project number PN-II-ID-PCE-2011-3-0094. The second author thanks the Visiting Professor Programming at King Saud University for funding this work. The fourth author extends his sincere appreciation to the Deanship of Scientific Research at King Saud University for its funding this Prolific Research Group (PRG-1436-10).

Received: 29 August 2015 Accepted: 4 December 2015 Published online: 22 December 2015

\section{References}

1. Perov, Al: On the Cauchy problem for a system of ordinary differential equations. Približ. Metody Rešen. Differ. Uravn. 2, 115-134 (1964)

2. Agarwal, RP: Contraction and approximate contraction with an application to multi-point boundary value problems. J. Comput. Appl. Math. 9, 315-325 (1983)

3. O'Regan, D, Shahzad, N, Agarwal, RP: Fixed point theory for generalized contractive maps on spaces with vector-valued metrics. In: Fixed Point Theory and Applications, vol. 6, pp. 143-149. Nova Science Publishers, New York (2007)

4. Petruęl, A, Petruşel, G: Nonlinear dynamics, fixed points and coupled fixed points in generalized gauge spaces with applications to a system of integral equations. Discrete Dyn. Nat. Soc. 2015, Article ID 143510 (2015). doi:10.1155/2015/143510

5. Precup, R, Viorel, A: Existence results for systems of nonlinear evolution equations. Int. J. Pure Appl. Math. 47(2), 199-206 (2008)

6. Precup, R, Viorel, A: Existence results for systems of nonlinear evolution inclusions. Fixed Point Theory 11(2), 337-346 (2010)

7. Precup, R: The role of matrices that are convergent to zero in the study of semilinear operator systems. Math. Comput. Model. 49, 703-708 (2009)

8. Czerwik, S: Nonlinear set-valued contraction mappings in b-metric spaces. Atti Semin. Mat. Fis. Univ. Modena 46, 263-276 (1998)

9. Bourbaki, N: Topologie Générale. Hermann, Paris (1974)

10. Bakhtin, IA: The contraction mapping principle in almost metric spaces. In: Functional Analysis, vol. 30, pp. 26-37. Ulianowsk Gos. Ped. Inst, Ulianowsk (1989)

11. Blumenthal, LM: Theory and Applications of Distance Geometry. Clarendon, Oxford (1953)

12. Opoitsev, Vl: Heterogenic and combined-concave operators. Sib. Math. J. 16, 781-792 (1975) (in Russian) 
13. Opoitsev, Vl: Dynamics of collective behavior. III. Heterogenic systems. Avtom. Telemeh. 36, 124-138 (1975) (in Russian)

14. Opoitsev, VI, Khurodze, TA: Nonlinear Operators in Spaces with a Cone. Tbilisi Gos. Univ., Tbilisi (1984) (in Russian)

15. Guo, D, Lakshmikantham, V: Coupled fixed points of nonlinear operators with applications. Nonlinear Anal. 11, 623-632 (1987)

16. Gnana Bhaskar, T, Lakshmikantham, V: Fixed point theorems in partially ordered metric spaces and applications. Nonlinear Anal. 65, 1379-1393 (2006)

17. Lakshmikantham, V, Ćirić, L: Coupled fixed point theorems for nonlinear contractions in partially ordered metric spaces. Nonlinear Anal. 70, 4341-4349 (2009)

18. Guo, D, Cho, YJ, Zhu, J: Partial Ordering Methods in Nonlinear Problems. Nova Science Publishers, New York (2004)

19. Berinde, V: Generalized coupled fixed point theorems for mixed monotone mappings in partially ordered metric spaces. Nonlinear Anal. 74, 7347-7355 (2011)

20. Boriceanu-Bota, M, Petruşel, A, Rus, IA: Fixed point theorems for some multivalued generalized contractions in b-metric spaces. Int. J. Math. Stat. 6, 65-76 (2010)

21. Samet, B: Coupled fixed point theorems for a generalized Meir-Keeler contraction in partially ordered metric spaces. Nonlinear Anal. 72(12), 4508-4517 (2010)

22. Zabrejko, PP: K-Metric and K-normed linear spaces: survey. Collect. Math. 48(4-6), 825-859 (1997)

23. Varga, RS: Matrix Iterative Analysis. Springer Series in Computational Mathematics, vol. 27. Springer, Berlin (2000)

24. Allaire, G, Kaber, SM: Numerical Linear Algebra. Texts in Applied Mathematics, vol. 55. Springer, New York (2008)

25. Berinde, V: Generalized contractions in quasimetric spaces. In: Seminar on Fixed Point Theory, pp. 3-9 (1993)

26. Urs, C: Coupled fixed point theorems and applications. Miskolc Math. Notes 14(1), 323-333 (2013)

27. Petruşel, A, Petruşel, G, Samet, B, Yao, J-C: Coupled fixed point theorems for symmetric contractions in b-metric spaces with applications to a system of integral equations and a periodic boundary value problem (submitted)

28. Petruşel, A, Rus, IA: Fixed point theorems in ordered L-spaces. Proc. Am. Math. Soc. 134(2), $411-418$ (2005)

\section{Submit your manuscript to a SpringerOpen ${ }^{\circ}$ journal and benefit from:}

- Convenient online submission

Rigorous peer review

- Immediate publication on acceptance

Open access: articles freely available online

- High visibility within the field

- Retaining the copyright to your article 